\title{
Treatment of Rheumatoid Arthritis with Certolizumab Pegol: Results from PROACTIVE, a Non-Interventional Study in the UK and Ireland
}

\author{
Namita Kumar · Sophia Naz • Mark Quinn · John Ryan • \\ Thomas Kumke · Tom Sheeran
}

Received: May 11, 2018 / Published online: August 3, 2018

(C) The Author(s) 2018

\begin{abstract}
Introduction: The objective of this non-interventional study was to investigate the longterm safety and effectiveness of certolizumab pegol (CZP) in patients with rheumatoid arthritis (RA) in the UK and Ireland.

Methods: Patients were prescribed CZP at their physicians' discretion and followed during routine clinical practice for up to 88 weeks.
\end{abstract}

Enhanced digital features To view enhanced digital features for this article go to https://doi.org/10.6084/ m9.figshare.6839597.

Electronic supplementary material The online version of this article (https://doi.org/10.1007/s12325018-0758-1) contains supplementary material, which is available to authorized users.

N. Kumar ( $\square)$

University Hospital of North Durham, Durham, UK

e-mail: Namita.Kumar@hee.nhs.uk

S. Naz

North Manchester General Hospital, Manchester,

UK

M. Quinn

York Hospital, York, UK

J. Ryan

Cork University Hospital, Cork, Ireland

T. Kumke

UCB Pharma, Monheim, Germany

T. Sheeran

Cannock Chase Hospital, Cannock, UK
DAS28(ESR) response (defined as at least a 1.2point reduction from baseline) was measured in the full analysis set (FAS) at week 12, and patients were categorized by week 12 responder status in all subsequent analyses. The primary outcome was DAS28(ESR) response at week 78. Secondary outcomes included change from baseline in DAS28(ESR), HAQ-DI, and RADAI scores at week 78, and EULAR response at week 78. Adverse drug reactions (ADRs) were recorded for all patients who received at least one dose of CZP.

Results: A total of 149 patients were enrolled, of whom 111 (74.5\%) formed the FAS. At week 12,80 patients $(72.1 \%)$ were DAS28(ESR) responders and 31 (27.9\%) non-responders. Compared to non-responders, a greater proportion of week 12 responders had a DAS28(ESR) response at week 78 (43.8\% versus 22.6\%). Improvements in DAS28(ESR), HAQ-DI, and RADAI scores were also greater on average among week 12 responders, as was the proportion of patients meeting EULAR criteria. Overall, 9 patients (6.1\%) experienced 13 ADRs during the study.

Conclusion: These data demonstrate the safety and effectiveness of CZP in adult patients with RA treated during routine clinical practice in the UK and Ireland.

Trial Registration: ClinicalTrials.gov identifier, NCT01288287.

Funding: UCB Pharma. 
Keywords: Anti-TNF; Arthritis; Certolizumab pegol; DAS28; DMARDs (biologic); Rheumatoid arthritis; Rheumatology

\section{INTRODUCTION}

Although the treatment options available for rheumatoid arthritis (RA) have expanded considerably over the past decade, patients who do not receive adequate treatment in the early stages of disease may experience progressive joint damage and substantial functional impairment $[1,2]$.

Certolizumab pegol (CZP) is an Fc-free, PEGylated anti-tumor necrosis factor (anti-TNF) that has demonstrated rapid efficacy and an acceptable safety profile in clinical studies of patients with RA [3-7]. Moreover, there is evidence that early response to CZP may be sustained in the long term, at least in a trial context [8, 9]. For example, patients treated with CZP in the RAPID 1 study experienced improvements in clinical and patient-reported outcomes after 1 week, which were maintained over 1 year [7]. Similar outcomes have been observed in a German non-interventional study (NCT01069419) [10], in which patients treated with CZP during routine clinical practice achieved a rapid reduction of disease activity by week 12, which was maintained to week 52 . However, there are currently limited real-world data describing these outcomes in the UK and Ireland.

Here we report data from a long-term, noninterventional study designed to investigate the safety and effectiveness of CZP in patients with $\mathrm{RA}$ treated during routine clinical practice in the UK and Ireland.

\section{METHODS}

\section{Patients}

Patients were aged 18 years or more, screened negative for tuberculosis [11], and had been prescribed CZP in line with the Summary of Product Characteristics (SmPC) [12] and the National Institute for Health and Care
Excellence (NICE) guidelines on the use of antiTNF agents in RA [13]. Concomitant use of methotrexate (MTX) and other conventional disease-modifying antirheumatic drugs (DMARDs) was permitted throughout this study.

Patients were excluded if they had prior biological DMARD exposure, had ever participated in a study of CZP, or had participated in a study for any other investigational medication within 30 days prior to study baseline. Patients with any contraindications specified in the SmPC were also excluded, including known hypersensitivity to any components of CZP; active tuberculosis or other severe infections; and moderate to severe heart failure.

All patients were considered both competent and willing to adhere to study procedures and had agreed to an 18-month follow-up period, regardless of any changes in treatment course during that time. All procedures performed were reviewed by two independent ethics committees (one for the UK and one for the Republic of Ireland), and were compliant with the 1964 Helsinki declaration and its later amendments. Informed consent was obtained from all individual participants included in the study.

\section{Study Design}

This was a prospective, observational, postmarketing study designed to assess long-term clinical and patient-reported outcomes, as well as changes in healthcare resource utilization, in patients with RA receiving CZP during routine clinical practice.

This study was conducted at 22 sites: 21 in the UK and one in the Republic of Ireland. Due to the non-interventional nature of this study, visits were not planned in the protocol, but were scheduled in line with routine clinical practice. As such, data were collected at weeks 4 ( \pm 1 week), 8 ( \pm 1 week), 12 ( \pm 2 weeks), 26 ( \pm 2 weeks), 52 ( \pm 2 weeks), 78 ( \pm 2 weeks), and 88 ( \pm 1 week). Patient enrollment and followup took place between July 2011 and December 2014. The decision to initiate treatment with CZP was made entirely at the discretion of the 
treating physician and was not influenced by the study protocol. Dosing decisions were also made by the physician in line with the SmPC [12].

Patients prescribed CZP were assessed and followed up as per clinical practice. Measures of effectiveness assessed through questionnaires or interviews were completed either at standard visits to the clinic or via telephone contact by the research nurse. All patients who had been prescribed and taken at least one dose of CZP were followed up by the clinician for up to 88 weeks, regardless of any changes to their treatment regimen, unless they withdrew consent or were lost to follow-up.

\section{Study Procedures and Evaluations}

The primary effectiveness variable was 28 -joint Disease Activity Score calculated with erythrocyte sedimentation rate (DAS28[ESR]) response at week 78, summarized by week 12 response group. DAS28(ESR) response was defined as a reduction from baseline by at least 1.2 points [14]. Subgroup analyses were performed to investigate the impact of age (less than 65 or at least 65 years), gender, rheumatoid factor (RF) status, and anti-citrullinated protein antibody (ACPA) status, on DAS28(ESR) response.

Secondary effectiveness variables included change from baseline in DAS28(ESR), Health Assessment Questionnaire-Disability Index (HAQ-DI), and Rheumatoid Arthritis Disease Activity Index (RADAI) scores at week 78, as well as European League Against Rheumatism (EULAR) response [15] at week 78.

Other effectiveness variables included changes in workplace and household productivity [assessed using the validated Work Productivity Survey (WPS) [16]] and patient quality of life [assessed using the Euro Quality of Life with five dimensions and three levels (EQ-5D-3L) questionnaire]. Patients' level of satisfaction with their current symptom state was assessed at each visit using the Patient Acceptable Symptomatic State (PASS) tool, in which patients were asked to rate their current state by answering the following question with a "Yes/ No" response: "Considering the full range of activities you engage in as part of your normal everyday life, your level of pain, and your level of disability, if you were to remain in your present condition for the next few months, would you consider your current health state satisfactory?" [17]. Healthcare resource utilization data were collected at each clinic visit, including the number and length of hospitalizations, and the number of concurrent medical procedures not foreseen in the study protocol.

To ensure complete safety data collection, all adverse drug reactions (ADRs) occurring during the study (including those that recurred or worsened after the initial visit) were reported directly in a safety database. Adverse events were classified as ADRs when a causal relationship between the product and the occurrence was suspected by the reviewing healthcare professional. Signs or symptoms of RA were only recorded as ADRs if they changed considerably in nature or if they increased in frequency and/ or intensity in a clinically significant manner, compared to the patient's clinical history or their clinical profile at baseline. An ADR was followed until it resolved, had stable sequelae, was determined by the treating physician to no longer be clinically significant, or the patient was lost to follow-up.

Adverse events considered by the investigator to be unrelated to CZP were not collected for this study, with the exception of adverse events of interest.

Safety data were summarized for the safety set (SS; all patients who received at least one dose of CZP) and effectiveness data for the full analysis set (FAS; all patients in the SS who had valid DAS28[ESR] values at baseline and at week 12).

\section{Statistical Analysis}

The optimal sample size for this study was calculated using a two-sided chi-squared test. Based on an analysis of DAS28(ESR) response data from the RAPID 1 study [18], the sample size required to detect a $30 \%$ difference in week 78 DAS28(ESR) response between week 12 responders and non-responders was estimated at $N=149$, with $\alpha=0.05$ and $90 \%$ power. 
A dropout rate of $20 \%$ at week 12 was anticipated, requiring a total of 187 patients to be recruited. However, an interim analysis at week 12 revealed a dropout rate of $5.3 \%$, based on 136 enrolled patients. As such, enrollment was ceased after 149 patients. This resulted in a loss of power of $5 \%$. All variables were analyzed in an exploratory manner using descriptive statistics.

Categorical variables were summarized as the frequency of response versus non-response (with 95\% confidence intervals [CI] for the primary effectiveness variable), and continuous variables as the mean and standard deviation (SD). Missing data were imputed using non-responder imputation (NRI) for categorical variables and last observation carried forward (LOCF) for continuous variables.

\section{RESULTS}

\section{Patient Disposition and Baseline Characteristics}

A total of 149 patients were enrolled in the study, of whom 147 (98.7\%) formed the SS and $111(74.5 \%)$ the FAS. Most enrolled patients $(68.5 \%)$ followed the study to completion (Fig. 1).

In the SS, most patients were female $(68.7 \%)$ and the mean (SD) age of participants was 55.6 (11.9) years. About three quarters (75.5\%) of the SS were aged less than 65 years and the majority of patients $(70.1 \%)$ were undergoing concomitant treatment with MTX (Table 1). In the FAS, most patients had high $(73.9 \%)$ or moderate (23.4\%) disease activity at baseline, as measured by DAS28(ESR) (Table 1).

\section{Effectiveness}

\section{DAS28(ESR) Response Rates at Week 78 by Week 12 Responder Status}

At week 12, 80 patients $(72.1 \%)$ were DAS28(ESR) responders and 31 (27.9\%) were non-responders. These data were used to divide patients into two groups-week 12 responders and week 12 non-responders-which formed

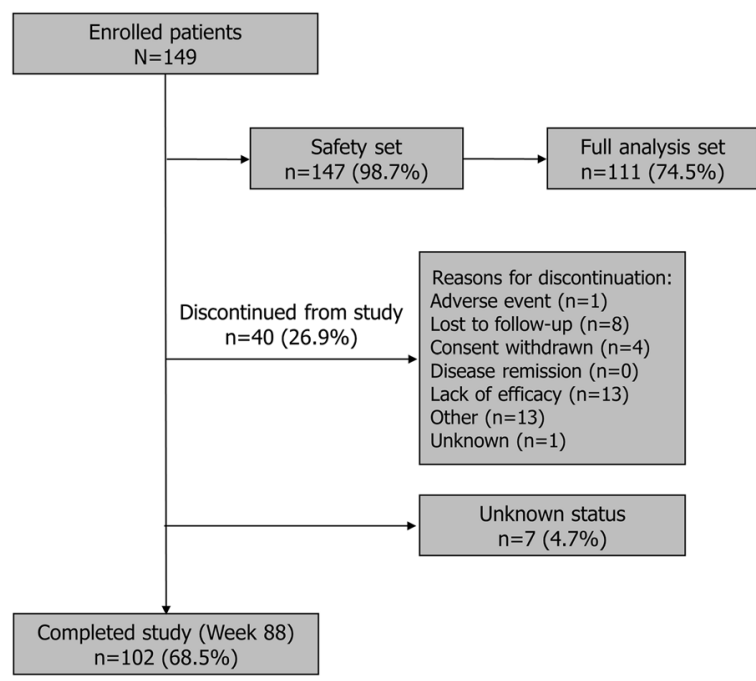

Fig. 1 Patient disposition. Percentages are based on the number of patients enrolled. A total of 60 patients (40.3\%) discontinued from CZP during the course of this study [6 (10.0\%) due to intolerance, $39(65.0 \%)$ due to lack of efficacy, and 15 (25.0\%) for other reasons]. The safety set comprised all patients who received at least one dose of CZP. The full analysis set comprised all patients who received at least one dose of CZP and had valid DAS28(ESR) values at baseline and at week 12 ( \pm 2 weeks)

the basis for all subsequent effectiveness analyses.

At week 78, a greater proportion of week 12 responders [43.8\%, $n=35(95 \%$ CI 32.7, 55.3)] than non-responders $[22.6 \%, n=7(9.6,41.1)]$ had a DAS28(ESR) response (Fig. 2). Subgroup analyses suggested that this trend was consistent between genders: among men, week 78 response rate was $50.0 \%(n=12)$ in week 12 responders and $0 \%$ in non-responders, while in women, it was $41.1 \%(n=23)$ and $33.3 \%$ $(n=7)$, respectively. Analysis by age group indicated a similar pattern: among patients aged less than 65 years, week 78 response rate was $40.0 \%(n=24)$ in week 12 responders and $26.1 \%(n=6)$ in non-responders, while in those aged 65 years or more, it was $55.0 \%(n=11)$ and $12.5 \%(n=1)$, respectively.

Similar trends were evident upon subgroup analysis by RF status and ACPA presence. For example, in RF-positive patients, week 78 response was $48.9 \% \quad(n=22)$ in week 12 
Table 1 Baseline demographics and disease characteristics

\begin{tabular}{|c|c|}
\hline Characteristic & $\operatorname{SS}(n=147)$ \\
\hline Age (years), mean (SD) & $55.6(11.9)$ \\
\hline Age $<65$ years, $n(\%)$ & $111(75.5)$ \\
\hline Age $\geq 65$ years, $n(\%)$ & $36(24.5)$ \\
\hline Female, $n(\%)$ & $101(68.7)$ \\
\hline RF positive, $n(\%)^{\mathrm{a}}$ & $69(65.1)$ \\
\hline ACPA positive, $n(\%)^{\mathrm{a}}$ & $42(53.8)$ \\
\hline Concomitant medications, $n(\%)$ & SS $(n=147)$ \\
\hline Specific antirheumatic agents & $107(72.8)$ \\
\hline Methotrexate & $103(70.1)$ \\
\hline $\begin{array}{l}\text { Non-specific anti-inflammatory and } \\
\text { antirheumatic agents }\end{array}$ & $46(31.3)$ \\
\hline Naproxen & $12(8.2)$ \\
\hline Ibuprofen & $9(6.1)$ \\
\hline Diclofenac & $8(5.4)$ \\
\hline Non-opioid analgesics and antipyretics & $25(17.0)$ \\
\hline Paracetamol & $24(16.3)$ \\
\hline $\begin{array}{l}\text { Antiparasitic products, insecticide and } \\
\text { repellent }\end{array}$ & $52(35.4)$ \\
\hline Antimalarials & $52(35.4)$ \\
\hline Hydroxychloroquine & $49(33.3)$ \\
\hline Alimentary tract and metabolic agents & $49(33.3)$ \\
\hline Sulfasalazine & $44(29.9)$ \\
\hline $\begin{array}{l}\text { Drugs for peptic ulcer and } \\
\text { gastroesophageal reflux }\end{array}$ & $8(5.4)$ \\
\hline $\begin{array}{l}\text { Systemic hormonal preparations } \\
\text { (excluding sex hormones) }\end{array}$ & $36(24.5)$ \\
\hline Corticosteroids & $35(23.8)$ \\
\hline Prednisolone & $29(19.7)$ \\
\hline Methylprednisolone acetate & $9(6.1)$ \\
\hline Triamcinolone & $1(0.7)$ \\
\hline Triamcinolone acetonide & $1(0.7)$ \\
\hline $\begin{array}{l}\text { Antineoplastic and immunomodulating } \\
\text { agents }\end{array}$ & $17(11.6)$ \\
\hline Leflunomide & $16(10.9)$ \\
\hline
\end{tabular}

Table 1 continued

\begin{tabular}{lc}
\hline Cardiovascular system agents & $8(5.4)$ \\
Disease characteristics & FAS $(n=111)$ \\
DAS28(ESR) score at baseline, mean & $5.7(1.1)$ \\
$(\mathrm{SD})$ & \\
Baseline disease activity, based on & \\
DAS28(ESR) score, $n(\%)$ & $1(0.9)$ \\
Remission $(<2.6)$ & $2(1.8)$ \\
Low disease activity $(2.6$ to $\leq 3.2)$ & $26(23.4)$ \\
Moderate disease activity $(>3.2$ & \\
to $\leq$ 5.1) & $82(73.9)$ \\
High disease activity $(>5.1)$ & $1.7(0.7)$ \\
HAQ-DI score at baseline, mean $(\mathrm{SD})$ & $5.8(1.6)$ \\
RADAI score at baseline, mean $(\mathrm{SD})$ &
\end{tabular}

$A C P A$ anti-citrullinated protein antibody, DAS28(ESR) 28 -joint count disease activity score, calculated with erythrocyte sedimentation rate, $F A S$ full analysis set, $H A Q-D I$ health assessment questionnaire-disability index, $R A D A I$ rheumatoid arthritis disease activity index, $R F$ rheumatoid factor, $S S$ safety set

a Proportions of the total number of patients who underwent the respective tests (RF test, $n=106$; ACPA test, $n=78$ )

responders and $11.1 \%(n=2)$ in week 12 nonresponders, while in RF-negative patients, the proportions were $41.2 \%(n=7)$ and $30.0 \%$ $(n=3)$, respectively (Supplementary Fig. 1). Similarly, in ACPA-positive patients, the week 78 response rate was $33.3 \%(n=9)$ in week 12 responders and $18.2 \%(n=2)$ in week 12 nonresponders, while in ACPA-negative patients, it was $42.1 \%(n=8)$ and $20.0 \%(n=2)$, respectively (Supplementary Fig. 1).

\section{Secondary Effectiveness Outcomes}

On average, the mean change from baseline in DAS28(ESR), HAQ-DI, and RADAI scores was greater among week 12 responders than nonresponders, across all relevant time points (Fig. 3).

Similarly, a greater proportion of week 12 responders met the criteria for a "good" EULAR 


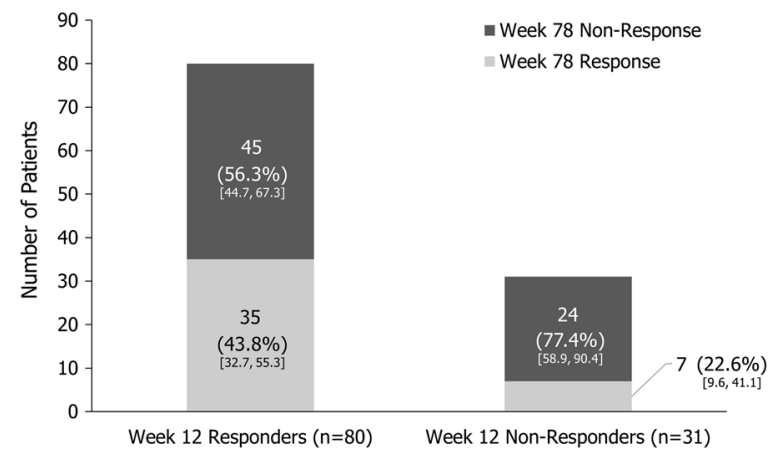

Fig. 2 DAS28(ESR) response at week 78 by week 12 DAS28(ESR) responder status. Full analysis set $(n=111)$. NRI imputation. 95\% confidence intervals are reported in square brackets. DAS28(ESR) 28-joint count disease activity score, calculated with erythrocyte sedimentation rate; NRI non-responder imputation

response at week 78 [41.3\% $(n=33)$, compared to $16.1 \%(n=5)$ of non-responders], while a greater proportion of week 12 non-responders failed to meet the EULAR response criteria [45.2\% $(n=14)$, compared to $18.8 \%(n=15)$ of responders]. The proportions of week 12 responders and non-responders who met the criteria for a "moderate" EULAR response were approximately equal (Fig. 4).

\section{Other Effectiveness Outcomes}

The mean length of hospitalization during the study was comparable between week 12 responders (3.13 days) and non-responders (2.33 days), although the mean number of concomitant medical procedures was greater among non-responders (5.0 versus 1.0) (Supplementary Table 1). Overall, there was little change in employment status in either group, and improvements in workplace and household productivity were comparable (Supplementary Tables 2 and 3).

At baseline, the PASS response was "No" (indicating an unacceptable symptom state, from the patient's perspective) for $91.0 \%$ $(n=101)$ of patients, and "Yes" for $9.0 \%$ $(n=10)$ of patients. By week 12 , however, more than half of patients $(55.9 \%, n=62)$ indicated satisfaction with their present symptom state. In each subsequent visit, the majority of week 12 responders had an acceptable PASS response.
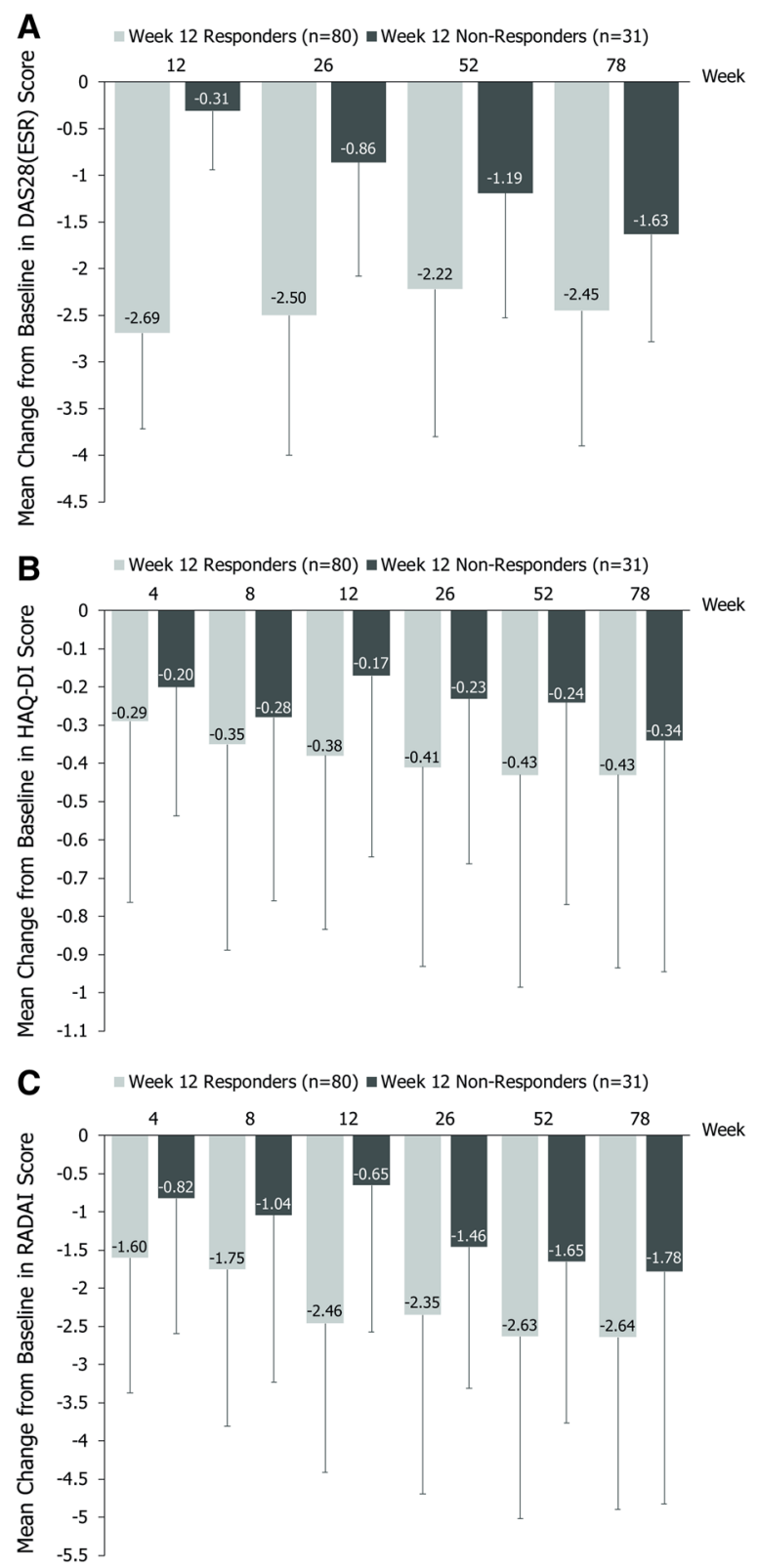

Fig. 3 Mean change from baseline in a DAS28(ESR), b HAQ-DI, and c RADAI scores by week 12 DAS28(ESR) responder status. Graphs present observed values for the full analysis set $(n=111)$, although patient numbers vary between measures and across time points. Error bars correspond to the standard deviation. DAS28(ESR) 28-joint count disease activity score, calculated with erythrocyte sedimentation rate; HAQ-DI health assessment questionnaire-disability index; RADAI rheumatoid arthritis disease activity index 


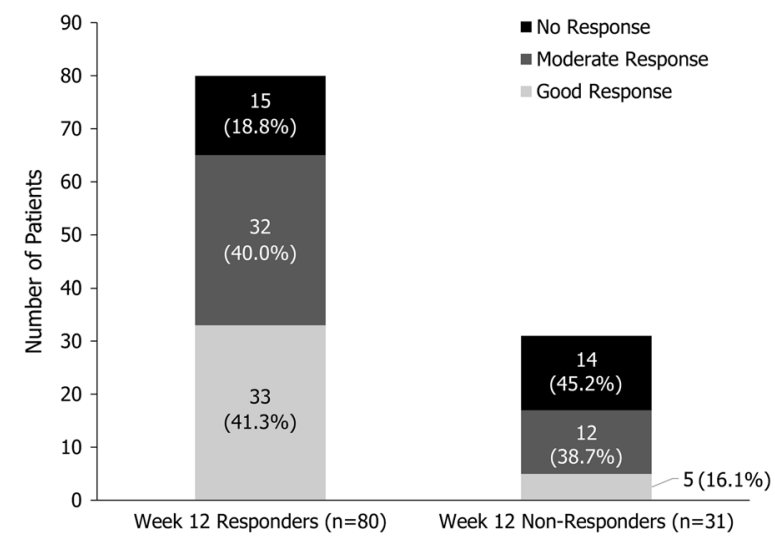

Fig. 4 EULAR response at week 78 by week 12 DAS28(ESR) responder status. Full analysis set $(n=111)$. LOCF imputation for week 12 DAS28(ESR) values. $D A S 28$ (ESR) 28-joint count disease activity score, calculated with erythrocyte sedimentation rate; EULAR European League Against Rheumatism; LOCF last observation carried forward

Moreover, the proportion of week 12 responders with an acceptable PASS response consistently exceeded that of non-responders (Supplementary Table 4).

The mean overall EQ-5D score improved from 49.38 at baseline to 60.63 at week 12 (mean change from baseline 11.68) and remained fairly consistent through to week 78 . Among week 12 responders, the greatest mean change from baseline was at week 12 (15.10) and was comparable at week 78 (13.45). By contrast, week 12 non-responders reported little change from baseline in EQ-5D score at weeks 12 and 26 (2.92 and 3.08, respectively), with an increase at week 52 (10.96) that declined again by week 78 (6.72) (Supplementary Table 5).

\section{Safety}

The median duration of exposure to CZP in this study was 606.5 days (range 70-786 days). Overall, nine patients (6.1\%) experienced 13 ADRs (Table 2).

Two cases of pulmonary tuberculosis were reported in this study. One was in a 52-year-old man, who developed tuberculosis approximately 26 months after initiation of CZP. The patient was considered negative for tuberculosis
Table 2 Adverse drug reactions

\begin{tabular}{ll}
\hline Category & $\boldsymbol{n}(\%)[\#$ of events] \\
\hline ADRs & $9(6.1)[13]$ \\
Serious ADRs & $9(6.1)[10]$ \\
AEs of interest & $4(2.7)[4]$ \\
Discontinuations due to ADRs & $1(0.7)[1]$ \\
\hline
\end{tabular}

Safety set $(n=147)$

$A D R$ adverse drug reaction, $A E$ adverse event

at screening [11]. The event resolved following 6 months' treatment with rifampicin, isoniazid, ethambutol, and pyridoxine. CZP was then restarted, and the patient completed the study. The reporting physician considered the event to be related to CZP. No further information was available regarding the patient's medical history, prior tuberculosis status, or the medical testing, evaluation, or treatment of his tuberculosis, and there was insufficient documentation to confirm that the pathogen was Mycobacterium tuberculosis.

The second case was in a 59-year-old woman, who had a medical history notable for RA and hepatic steatosis, and developed pulmonary tuberculosis approximately 12 months after CZP initiation. The patient was started on Rifinah $^{\circledR} \quad$ (rifampicin/isoniazid), pyrazinamide, ethambutol, and pyridoxine for 2 months, and then reduced to Rifinah ${ }^{\circledR}$ and pyridoxine for 4 months. The tuberculosis was considered resolved approximately 7 months after diagnosis and starting treatment, and the patient restarted on CZP. The reporting physician considered the event to be related to CZP. No further information was available regarding the patient's prior tuberculosis status.

There was also one case of cellulitis, which was considered related to CZP and led to treatment discontinuation, and one of bladder cancer, for which causality was not known. No deaths were reported during this study.

\section{DISCUSSION}

Rheumatoid arthritis is a chronic, disabling condition with a considerable impact on quality 
of life $[2,19,20]$ and a substantial economic burden [21-24]. CZP has proven to be an efficacious option for the treatment of RA in numerous clinical studies, with an acceptable safety profile [3-7]. However, despite the prevalence [25-27] and economic burden $[28,29]$ of this disease in the UK and Ireland, there are limited real-world data describing the clinical response to CZP in these countries.

In this non-interventional study, we followed adult patients with RA receiving CZP during routine clinical practice in the UK and Ireland. Our findings revealed that this population responds to treatment with CZP in a similar manner to patients enrolled in the RAPID 1 and 2 clinical trials [6, 7], in which a clinical response to CZP was evident from as early as 1 week [7] (in the present study, clinical improvements were observed at 4 weeks, the earliest available time point).

Moreover, we present data indicating that a greater proportion of week 12 DAS28(ESR) responders (compared to week 12 non-responders) have a DAS28(ESR) response at week 78. These findings were consistent when subgroup analyses were performed by gender, age, RF status, and ACPA presence, although patient numbers were low in some groups, precluding any definite conclusions based on these comparisons. A similar proportion of week 12 responders met the criteria for EULAR response at week 78, which incorporates both current DAS28(ESR) score and change from baseline, and thus provides a more stringent measure of effectiveness over time. Collectively, these data suggest that early response to CZP may be indicative of future response, at least to 78 weeks. This builds on observations from randomized controlled trials: for example, a post hoc analysis of the RAPID 1 trial revealed that attainment of clinical response to CZP at week 12 was associated with better clinical and radiographic outcomes at week 52, compared to week 12 non-responders [30].

The observed improvements in clinical measures were closely reflected by changes in patients' self-reported disease activity. The RADAI is a self-administered questionnaire that combines five items into a single index and has been validated for use in RA [31]. Improvements in the RADAI were generally evident through to week 78 and again these improvements were more pronounced among week 12 responders. Although a more recent tool-the RADAI-5has since been developed to enhance reliability, a high degree of correlation has been noted between the two instruments [32], suggesting that our data remain strongly indicative of selfreported disease activity over time.

Among the other self-reported measures of effectiveness used in this study was the PASS, which allows patients to express their satisfaction with their current symptom state (or lack thereof) through a simple "Yes/No" response [17]. Although the PASS is not widely used in RA studies, it is a rapid, patient-reported, and easily comprehensible tool that has previously been shown to discriminate patients with RA [33] and systemic lupus erythematosus [34] on the basis of disease activity. While the RADAI shares some of these characteristics (ease of use, selfadministration), it requires patient responses to multiple items and thus may be biased by missing data. The RADAI may also be more difficult to interpret, given that it represents a summation of several measures in a single index [31]. These shortcomings arguably make the PASS a more valuable instrument for use in clinical trials, although issues pertaining to cross-cultural validity, as well as the discordance between PASS response and disease activity [35], should be considered. In the present study, a positive PASS response appeared to correspond to week 12 responder status: a greater proportion of those who responded to CZP treatment at week 12 reported satisfaction with their symptoms at subsequent time points. This may be a first step towards indicating the utility of the PASS as a surrogate marker for RA clinical trials; however, extensive comparisons with conventional datasets will be necessary to substantiate this finding.

Since all participants had been prescribed CZP by their treating physician, this study was limited by the absence of a control group, and it is possible that the open-label nature of the study introduced some bias towards the reporting of effectiveness. Nevertheless, the findings presented in this report demonstrate the long-term effectiveness of CZP for the 
treatment of RA in a real-world setting. This is consistent with data from various open-label extension studies, in which CZP was shown to be effective and to have an acceptable safety profile over several years of treatment in patients with RA [18, 36, 37].

The results of this study position CZP alongside a panel of anti-TNF agents that have demonstrated real-world effectiveness in the treatment of RA [38-40]. Moreover, the safety outcomes reported for this patient population were in line with the known safety profile for anti-TNF inhibitors [41-44], and no new safety signals emerged when administering CZP in a real-world setting [45]. The ADR rate observed in this study was lower than that seen in many other studies, which may be attributable to its non-interventional nature (comparatively low rates of ADRs are an established phenomenon in non-interventional studies [46]). In addition, it is important to note that adverse events considered unrelated to CZP treatment were not recorded in this study, which may have contributed to the low reported rate.

\section{CONCLUSIONS}

The data presented in this report indicate that CZP is an effective treatment for adult patients with RA in a clinical setting in the UK and Ireland. Thus, CZP may form part of treat-to-target strategy for this patient population, both improving patients' quality of life and reducing the economic burden of disease in these countries.

\section{ACKNOWLEDGEMENTS}

The authors thank the patients, the investigators, and their teams who took part in this study.

Funding. UCB Pharma (Brussels, Belgium) sponsored the study and the development of the manuscript and reviewed the text to ensure that from UCB's perspective, the data presented in the publication are scientifically, technically, and medically supportable, that they do not contain any information that has the potential to damage the intellectual property of UCB, and that the publication complies with applicable laws, regulations, guidelines, and good industry practice. The authors approved the final version to be published after critically revising the manuscript for important intellectual content. Article processing charges were also funded by UCB Pharma. All authors had full access to all of the data in this study and take complete responsibility for the integrity of the data and accuracy of the data analysis.

Medical Writing and/or Editorial Assistance. The authors also acknowledge Susanne Wiegratz (UCB Pharma GmbH, Monheim am Rhein, Germany) for publication coordination and Sam Fraser, PhD (Costello Medical, Cambridge, UK) for medical writing and editorial assistance in preparing this manuscript for publication, based on the authors' input and direction. These activities were funded by UCB Pharma.

Authorship. All named authors meet the International Committee of Medical Journal Editors (ICMJE) criteria for authorship for this article, take responsibility for the integrity of the work as a whole, and have given their approval for this version to be published.

Disclosures. Thomas Kumke is an employee of UCB Pharma. Namita Kumar, Sophia Naz, Mark Quinn, John Ryan, and Tom Sheeran have nothing to disclose.

Compliance with Ethics Guidelines. All procedures performed were reviewed by two independent ethics committees (one for the UK and one for the Republic of Ireland) and were compliant with the 1964 Helsinki declaration and its later amendments. Informed consent was obtained from all individual participants included in the study.

Data availability. The datasets generated and/or analyzed during the current study are available from the corresponding author on reasonable request. 
Open Access. This article is distributed under the terms of the Creative Commons Attribution-NonCommercial 4.0 International License (http://creativecommons.org/licenses/ by-nc/4.0/), which permits any noncommercial use, distribution, and reproduction in any medium, provided you give appropriate credit to the original author(s) and the source, provide a link to the Creative Commons license, and indicate if changes were made.

\section{REFERENCES}

1. Palamar D, Er G, Terlemez R, Ustun I, Can G, Saridogan M. Disease activity, handgrip strengths, and hand dexterity in patients with rheumatoid arthritis. Clin Rheumatol. 2017;36(10):2201-8.

2. Rosa-Gonçalves D, Bernardes M, Costa L. Quality of life and functional capacity in patients with rheumatoid arthritis-cross-sectional study. Rheumatol Clin. 2017. https://doi.org/10.1016/j. reuma.2017.03.002.

3. Emery P, Bingham CO, Burmester GR, et al. Certolizumab pegol in combination with dose-optimised methotrexate in DMARD-naïve patients with early, active rheumatoid arthritis with poor prognostic factors: 1-year results from C-EARLY, a randomised, double-blind, placebo-controlled phase III study. Ann Rheum Dis. 2016;76:96-104.

4. Fleischmann R, Vencovsky J, van Vollenhoven RF, et al. Efficacy and safety of certolizumab pegol monotherapy every 4 weeks in patients with rheumatoid arthritis failing previous disease-modifying antirheumatic therapy: the FAST4WARD study. Ann Rheum Dis. 2009;68(6):805-11.

5. Keystone E, Heijde DVD, Mason D, et al. Certolizumab pegol plus methotrexate is significantly more effective than placebo plus methotrexate in active rheumatoid arthritis: findings of a fiftytwo-week, phase III, multicenter, randomized, double-blind, placebo-controlled, parallel-group study. Arthritis Rheum. 2008;58(11):3319-29.

6. Smolen J, Landewé RB, Mease P, et al. Efficacy and safety of certolizumab pegol plus methotrexate in active rheumatoid arthritis: the RAPID 2 study. A randomised controlled trial. Ann Rheum Dis. 2009;68(6):797-804.

7. Strand V, Mease P, Burmester GR, et al. Rapid and sustained improvements in health-related quality of life, fatigue, and other patient-reported outcomes in rheumatoid arthritis patients treated with certolizumab pegol plus methotrexate over 1 year: results from the RAPID 1 randomized controlled trial. Arthritis Res Ther. 2009;11(6):R170.

8. Curtis JR, Churchill M, Kivitz A, et al. A Randomized trial comparing disease activity measures for the assessment and prediction of response in rheumatoid arthritis Patients Initiating Certolizumab Pegol. Arthritis Rheumatol. 2015;67(12):3104-12.

9. Curtis JR, Luijtens K, Kavanaugh A. Predicting future response to certolizumab pegol in rheumatoid arthritis patients: features at 12 weeks associated with low disease activity at 1 year. Arthritis Care Res (Hoboken). 2012;64(5):658-67.

10. Burmester G, Müller-Ladner U, Nüsslein $H$, et al. AB0467 Rapid achievement of remission with certolizumab pegol was maintained for one year: interim results from fast, a German non-interventional study in rheumatoid arthritis real life patients. Ann Rheum Dis. 2013;71(Suppl 3):664.

11. British Thoracic Society Standards of Care Committee. BTS recommendations for assessing risk and for managing Mycobacterium tuberculosis infection and disease in patients due to start anti-TNF-alpha treatment. Thorax. 2005;60(10):800-5.

12. European Medicines Agency. Certolizumab pegol summary of product characteristics. http://www. ema.europa.eu/docs/en_GB/document_library/EPA R_-_Product_Information/human/001037/WC5000 69763.pdf. Accessed 8 June 2017.

13. National Institute for Health and Care Excellence. Rheumatoid arthritis in adults: management (Clinical guideline [CG79]) 2015. https://www.nice. org.uk/guidance/cg79/chapter/Recommendations\# pharmacological-management. Accessed 8 June 2017.

14. Ledingham J, Deighton C. Update on the British Society for Rheumatology guidelines for prescribing TNF $\alpha$ blockers in adults with rheumatoid arthritis (update of previous guidelines of April 2001). Rheumatology. 2005;44(2):157-63.

15. Fransen J, van Riel PL. The disease activity score and the EULAR response criteria. Rheum Dis Clin North Am. 2009;35(4):745-57.

16. Osterhaus JT, Purcaru O, Richard L. Discriminant validity, responsiveness and reliability of the rheumatoid arthritis-specific work productivity survey (WPS-RA). Arthritis Res Ther. 2009;11(3):R73.

17. Tubach F, Ravaud P, Beaton D, et al. Minimal clinically important improvement and patient 
acceptable symptom state for subjective outcome measures in rheumatic disorders. J Rheumatol. 2007;34(5):1188-93.

18. Keystone E, Landewé R, van Vollenhoven R, et al. Long-term safety and efficacy of certolizumab pegol in combination with methotrexate in the treatment of rheumatoid arthritis: 5-year results from the RAPID 1 trial and open-label extension. Ann Rheum Dis. 2014;73(12):2094-100.

19. Rigby W, Ferraccioli G, Greenwald M, et al. Effect of rituximab on physical function and quality of life in patients with rheumatoid arthritis previously untreated with methotrexate. Arthritis Care Res (Hoboken). 2011;63(5):711-20.

20. Salaffi F, Carotti M, Gasparini S, Intorcia M, Grassi W. The health-related quality of life in rheumatoid arthritis, ankylosing spondylitis, and psoriatic arthritis: a comparison with a selected sample of healthy people. Health Qual Life Outcomes. $2009 ; 7: 25$.

21. Hu H, Luan L, Yang K, Li S-C. Burden of rheumatoid arthritis from a societal perspective: a prevalencebased study on cost of illness for patients with rheumatoid arthritis in China. Int J Rheum Dis. 2017. https://doi.org/10.1111/1756-185X.13028

22. Kavanaugh A. Economic issues with new rheumatologic therapeutics. Curr Opin Rheumatol. 2007; 19:272-6.

23. Lundkvist J, Kastäng F, Kobelt G. The burden of rheumatoid arthritis and access to treatment: health burden and costs. Eur J Health Econ. 2008;8(2):49-60.

24. Mennini FS, Marcellusi A, Gitto L, Iannone F. Economic burden of rheumatoid arthritis in Italy: possible consequences on anti-citrullinated protein antibody-positive patients. Clin Drug Investig. 2017;37(4):375-86.

25. National Audit Office. Services for people with rheumatoid arthritis: international comparisons. 2009. https://www.nao.org.uk/wp-content/uploads/ 2009/07/0809823_international_comparisons.pdf. Accessed 24 Apr 2017.

26. Power D, Codd M, Ivers L, Sant S, Barry M. Prevalence of rheumatoid arthritis in Dublin, Ireland: a population based survey. Ir J Med Sci. 1999;168(3):197-200.

27. Symmons D, Turner G, Webb R, et al. The prevalence of rheumatoid arthritis in the United Kingdom: new estimates for a new century. Rheumatology. 2002;41(7):793-800.
28. Bevan S, Quadrello T, McGee R, Mahdon M, Vavrovsky A, Barham L. Fit for work? Musculoskeletal disorders in the European workforce 2009. http:// www.fitforworkeurope.eu/Website-Documents/Fit\% 20for\%20Work\%20pan-European\%20report.pdf. Accessed 30 June 2017.

29. National Rheumatoid Arthritis Society. The economic burden of rheumatoid arthritis 2010. https://www. nras.org.uk/data/files/Publications/1_economic_bur den_of_ra_final_30_3_10.pdf. Accessed 12 Mar 2018.

30. Keystone EC, Curtis JR, Fleischmann RM, et al. Rapid improvement in the signs and symptoms of rheumatoid arthritis following certolizumab pegol treatment predicts better longterm outcomes: posthoc analysis of a randomized controlled trial. J Rheumatol. 2011;38(6):990-6.

31. Fransen J, Langenegger $T$, Michel BA, Stucki G. Feasibility and validity of the RADAI, a self-administered rheumatoid arthritis disease activity index. Rheumatology. 2000;39(3):321-7.

32. Leeb BF, Haindl PM, Brezinschek HP, Nothnagl T, Rintelen B. RADAI-5 to monitor rheumatoid arthritis. Clin Exp Rheumatol. 2014;32(5 Suppl 85):S-55-8.

33. Salaffi F, Carotti M, Di Carlo M, De Angelis R, Gutierrez M. SAT0080 patient acceptable symptom state (PASS) in self-report questionnaires and composite clinical disease index for assessing rheumatoid arthritis. Identification of cut-off points for routine care. Ann Rheum Dis. 2015;74(Suppl 2):677.

34. Conti F, Ceccarelli F, Massaro L, et al. Evaluation of the Patient Acceptable Symptom State (PASS) in Italian patients affected by systemic lupus erythematosus: association with disease activity indices. PLoS One. 2013;8(9):e73517.

35. Kvien TK, Heiberg T, Hagen KB. Minimal clinically important improvement/difference (MCII/MCID) and patient acceptable symptom state (PASS): what do these concepts mean? Ann Rheum Dis. 2007;66(Suppl 3):iii40-iii1.

36. Fleischmann R, van Vollenhoven RF, Vencovský J, et al. Long-term maintenance of certolizumab pegol safety and efficacy, in combination with methotrexate and as monotherapy, rheumatoid arthritis patients. Rheumatol Ther. 2017;4(1):57-69.

37. Smolen JS, van Vollenhoven R, Kavanaugh A, et al. Certolizumab pegol plus methotrexate 5-year results from the rheumatoid arthritis prevention of structural damage (RAPID) 2 randomized controlled trial and long-term extension in rheumatoid arthritis patients. Arthritis Res Ther. 2015;17(1):245. 
38. Ceccarelli F, Massafra U, Perricone C, et al. AntiTNF treatment response in rheumatoid arthritis patients with moderate disease activity: a prospective observational multicentre study (MODERATE). Clin Exp Rheumatol. 2017;35(1):24-32.

39. D'Souza A, Meissner BL, Tang B, McKenzie RS, Piech CT. Effectiveness of anti-tumor necrosis factor agents in the treatment of rheumatoid arthritis: observational study. Am Health Drug Benefits. 2010;3(4):266-73.

40. Filippini M, Bazzani C, Favalli EG, et al. Efficacy and safety of anti-tumour necrosis factor in elderly patients with rheumatoid arthritis: an observational study. Clin Rev Allergy Immunol. 2010;38(2):90-6.

41. Aletaha D, Bingham CO III, Tanaka Y, et al. Efficacy and safety of sirukumab in patients with active rheumatoid arthritis refractory to anti-TNF therapy (SIRROUND-T): a randomised, double-blind, placebo-controlled, parallel-group, multinational, phase 3 study. Lancet. 2017;389(10075):1206-17.

42. Alten R, Kaine J, Keystone E, Nash P, Delaet I, Genovese MC. Long-term safety of subcutaneous abatacept in rheumatoid arthritis: integrated analysis of clinical trial data representing more than four years of treatment. Arthritis Rheumatol. 2014;66(8):1987-97.

43. Burmester GR, Landewé R, Genovese MC, et al. Adalimumab long-term safety: infections, vaccination response and pregnancy outcomes in patients with rheumatoid arthritis. Ann Rheum Dis. 2017;76(2):414-7.

44. Takeuchi T, Tatsuki Y, Nogami Y, et al. Postmarketing surveillance of the safety profile of infliximab in 5000 Japanese patients with rheumatoid arthritis. Ann Rheum Dis. 2008;67(2):189-94.

45. Bykerk VP, Cush J, Winthrop K, et al. Update on the safety profile of certolizumab pegol in rheumatoid arthritis: an integrated analysis from clinical trials. Ann Rheum Dis. 2015;74(1):96-103.

46. Ruof J, Iking-Konert C, Simianer S, Burmester G-R. Nichtinterventionelle Phase-IV-Studien zur Behandlung der rheumatoiden Arthritis mit Biologicals in Deutschland. Z Rheumatol. 2014;73(1):65-73. 